\title{
Endoscopic retrograde cholangiography after endoscopic ultrasound-related duodenal perforation: keep calm, use over-the-scope clip, and carry on!
}

The over-the-scope clip (OTSC) is a useful tool recommended as first-line endoscopic treatment for endoscopic acute iatrogenic perforation [1]. A retrospective study documented that OTSCs can avoid emergency surgical repair, allowing, in some cases, completion of the primary endoscopic procedure. As documented only once in the literature, its use could allow subsequent endoscopic procedures to be performed in the same session, owing to the endurance of the device during pneumatic and mechanical stress [2].

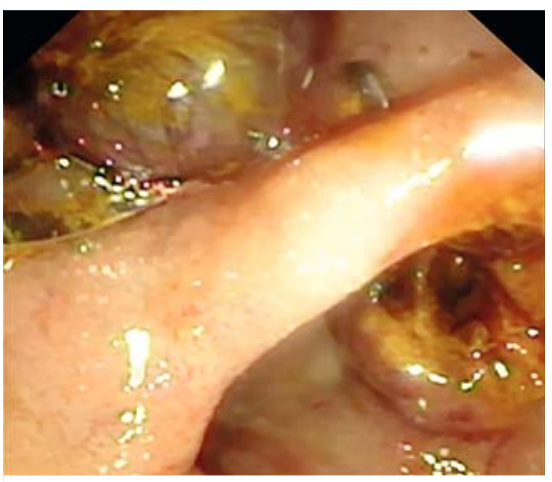

- Fig. 1 Endoscopic appearance at the end of prolonged pneumatic and mechanical stress during endoscopic retrograde cholangiography.

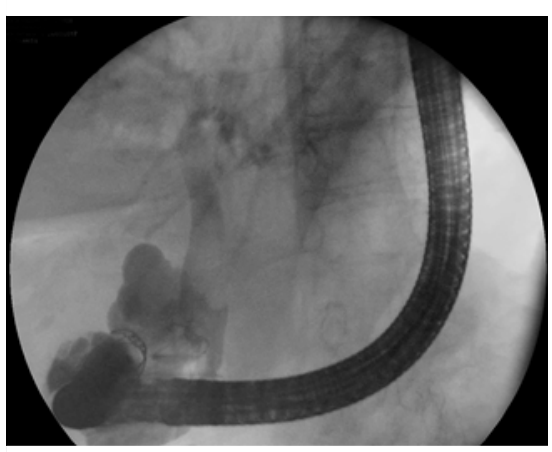

-Fig. 2 Radiological image showing no more leakage, even after the prolonged mechanical stress of complete biliary drainage.
Here we report the video case of a 93-year-old woman who was referred to our unit to undergo biliopancreatic endoscopic ultrasound (GF-UCT 180; Olympus Co., Tokyo, Japan) for suspected choledocholithiasis, in the context of acute cholangitis; the patient was not a suitable candidate for surgery (cholecystectomy).

After multiple biliary stones were detected in the common bile duct, a perforation was apparent in the wall of the superoanterior duodenal bulb. Because of the size of the perforation (about $15 \mathrm{~mm}$ ), an OTSC (11/6 mm traumatic type; Ovesco Endoscopy GmbH, Tübingen, Germany) was applied using the suction technique to completely seal the defect [3]. As no further leakage was apparent following injection of contrast medium and the patient's clinical condition was stable, endoscopic retrograde cholangiography (ERC; TJF-160 VR; Olympus Co.) with extraction of multiple biliary stones was performed in the same session ( $\vee$ Video 1 ).

All procedures were performed with anesthesiological assistance, using carbon dioxide insufflation. ERC took about 45 minutes for complete biliary drainage ( $\triangleright$ Fig. 1). The subsequent contrast medium ( $\triangleright$ Fig. 2) and computed tomography scan with oral gastrographin confirmed the complete closure, despite the longlasting pneumatic and mechanical stress. No further complication occurred and the asymptomatic patient was discharged 1 week later.

In conclusion, prompt endoscopic treatment using OTSCs represents an effective approach that can avoid later complications or surgical repair. Furthermore, the use of OTSCs can allow the completion of endoscopic procedure(s) in the same session, as the clips can endure prolonged pneumatic and mechanical stress.

Endoscopy_UCTN_Code_CPL_1AK_2AC

Competing interests

None 


\section{Bibliography}

DOI https://doi.org/10.1055/s-0043-115894

Paola Soriani ${ }^{1}$, Vincenzo Giorgio Mirante ${ }^{1}$, Carmelo Barbera ${ }^{1}$, Giuseppe Grande ${ }^{2}$, Lucia Miglioli ${ }^{1}$, Mauro Manno ${ }^{1}$

1 Digestive Endoscopy Unit, Azienda USL Modena, Ramazzini Hospital, Carpi, Italy

2 Gastroenterology and digestive Endoscopy Unit, OCSAE Hospital AOU Modena, Italy

\section{Corresponding author}

\section{Paola Soriani, MD}

Digestive Endoscopy Unit, Azienda USL Modena, Ramazzini Hospital, Via Molinari 2, Carpi, Modena, Italy Fax: +39-059-659500

[1] Paspatis GA, Dumonceau JM, Barthet M et al. Diagnosis and management of iatrogenic endoscopic perforations: European Society of Gastrointestinal Endoscopy (ESGE) Position Statement. Endoscopy 2014; 46: 693 711

[2] Donatelli G, Cereatti F, Dhumane P et al. Closure of gastrointestinal defects with Ovesco clip: long-term results and clinical implications. Ther Adv Gastroenterol 2016; 9: $713-721$

[3] Kobara H, Mori H, Fujihara S et al. Outcomes of gastrointestinal defect closure with an over-the-scope clip system in a multicentre experience: an analysis of a successful suction method. World J Gastroenterol 2017; 23: $1645-1656$
Published online: 3.8.2017

Endoscopy 2017; 49: E268-E269

(c) Georg Thieme Verlag KG

Stuttgart · New York

ISSN 0013-726X

\section{ENDOSCOPY E-VIDEOS}

https://eref.thieme.de/e-videos

回回 Endoscopy E-Videos is a free

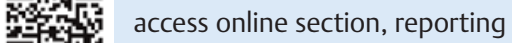
自: on interesting cases and new techniques in gastroenterological endoscopy. All papers include a high quality video and all contributions are freely accessible online.

This section has its own submission website at

https://mc.manuscriptcentral.com/e-videos 